\title{
XI. New method of rendering platina malleable. By Count Apollos Moussin Poushkin. Made public, at his request
}

\section{Charles Hatchett Esq. F.R.S.}

To cite this article: Charles Hatchett Esq. F.R.S. (1804) XI. New method of rendering platina malleable. By Count Apollos Moussin Poushkin. Made public, at his request, Philosophical Magazine Series 1, 20:77, 76-78, DOI: 10.1080/14786440408676598

To link to this article: http://dx.doi.org/10.1080/14786440408676598

Published online: 18 May 2009.

Submit your article to this journal $\pi$

山 Article views: 2

View related articles $\sqsubset$ 


\section{$\left[\begin{array}{ll}76 & ]\end{array}\right.$}

XI. New Method of rendering Platina malleable. By Count Apollos Moussin Poushicin. Made pullic, at his Request, by Charles Hatchett, Esq. F.R. S. *

1. Precipitate the platina from its solution by muriate of ammonia, and wash the precipitate with a little cold water.

9. Reduce it in a convenient crucible to the well-known spungy metallic texture; which wash two or three times with boiling water, to carry off any portion of saline matter which may have escaped the action of the fire.

3. Boil it for about half an hour in as much water mixed with one tenth part of muriatic acid as will cover the mass to the depth of about half an inch in a cenvenient glass vessel. This will carry off any quantity of iron that might still exist in the metal.

4. Decant the acid water, and edulcorate or strongly ignite the platina.

5. To one part of this metal take two parts of mercury, and amalgamate in a glass or porphyry mortar. This amalgamation takes place very readily. 'The proper method of conducting it is to take about two drams of mercury to three drams of platina, and amalgamate them together; and to this amalgam may be added alternate small quantities of platina and mercuny till the whole of the two metals are combined. Several pounds may be thus amalgamated in a few hours, and in the large way a proper mill might shorten the operation.

6. After the amalgam is completely produced, it must be quickly moulded in bars or plates, or any other forms that may be preferred; taking care that these moulded pieces should at least be half an inch in thickness, and of a proper length to manage them afterwards in the fire; it is also requisite that the moulds should be perfectly even and smooth. Half an hour after the pieces are formed they begin to harden by the oxidation of the mercury, and change their brilliant metallic colour for a dull leaden one.

7. As soon as the pieces have acquired a proper degree of hardness to be handled without danger of breaking, which commonly takes place in a little more than an hour, place them in a proper furnace, and keep them ignited under a mufile or in a small reverberatory. No other precau.

* From Nicholson's Journal, vol, ix. Oct. I 804. 
tion is necessary in this operation but that of not breaking the pieces during their transport. The mercury flies off during the heat, and the platina remains perfectly solid; so that, after being strongly ignited two or three times before the bellows, it may be forged or laminated in the same manner as gold or silver; care being taken, at the commencement of the forging, or of passing it between rollers, not to apply too great a force till the metal has acquired all its density. It is almost superfluous to add, that in evaporating the mercury from large quantities of amalgam, a proper apparatus, such as in the silver amalgamation, must be employed to receive the volatilized mercury; but for small quantities, where the loss of this metal is of no consequence, the furnace must have a proper chimney to carry of the metallic vapours. When the platina comes out of the first fire its dimensions are about two thirteenth parts smaller every way than the original amalgam from the mould. The whole of this operation seems to be governed by the pressure of the atmosphere and the laws of cohesive attraction; for the air is driven out from between the molecules of the platina, which by their solution in mercury are most probably in their primitive and consequently uniform figure. It is very visiblé, and at the same time a very amusing phænomenon to observe, (during the process of ignition, which is performed in four or five minutes) how the platina contracts every way into itself, as if pressed by some external force*.

I have also lately obtained triple salts of muriate of platina with muriate of ponderous earth; and also with muriate of magnesia; and I strongly suspect that every other earth except the siliceous, and even the metals, are susceptible of such triple combinations. I have likewise obtained a very beautiful salt of platina by the combination of soda and platina with the muriatic acid; a combination which Bergmın and several other chemists deny. The best manner of obtain-

* In the Count's letter to Mr. Hatchett, requesting him to publish the method in the text (communicated to $\mathrm{Mr}$. H. some years ago), the following addition is given: (in French.)

“As scon as my amalgam of mercury is made, I compress the same in tubes of wood, by the pressure of an iron screw upon a cylinder of wood, adapted to the bore of the tube. This forces out the superabundant mercury from the amalgam, and renders it solid. After two or three hours I burn upon the coals, or in a crucible lined with charcoal, the sheath in which the amalgam is contained, and urge the fire to a white heat; after which I take out the platina in a very solid state, fit to be forged." 
ing it is by dissolving the platina in nitrous acid, to which, for that purpose, two parts of muriate of soda and one of platina are added. The platina must be made in a retort with its receiver; and after about four fifths of the fluid have come over, the process must be interrupted, and the whole left to cool in the sand bath. The salt crystallizes in fine prisms, which are sometimes four or five inches long, and either red brown, like titanium, yellow, like amber, or of a beautiful coquelicot colour, according to the purity of the platina. I enclose here my address during my absence, and hope you will receive with indulgence the contents of this letter.

I am with great regard, sir,

Your most humble and obedient servant,

Count Apollos Moussin Poushkin.

XII. Notices respecting New Books.

$\mathrm{T}$ $\Gamma_{\text {HE physicians of the original Vaccine Pock Institution, }}$ established in 1799 , have lately published "A Statement of Evidence from Trials by Inoculation of Variolous and Vaccine Matter; to judge of the Question, Whether or not a Person can undergo the Small-Pox after being affected by the Cov-Pock," which is well deserving the attention of medical men. The chief object of the authors seems to have been to answer, by decisive experiments, the objections of Mr. Goldson, in a recent publication, questioning the efficacy of vaccine inoculation; and they have taken the best means to ascertain the question, namely, re-inoculating, with variolous matter, a number of patients who had some years ago been inoculated for the cow-pock. The experiments related show, that above fifty persons who had been vaccinated from three to five years ago, and ten who had been vaccinated at a later period, were incapable of taking the small-pox by inoculation in circumstances chosen as most favourable for infection. For many of the subjects were exposed to the effluvia from small-pox patients; they were all inoculated in three times the usual number of places; they were all inoculated with efficacious and recent matter; and with many of them unusual pains were bestowed to introduce the matter quite fluid immediately from the variolous patient. In these it seems fair to calculate that not more than one, or at most two, of these sixty persons would have escaped the small-pox, if they had not already gone 